\title{
Work careers of Chinese Republic Peers women
}

\author{
Jing Bian, Chao Lu \\ Department of Foreign Language University of Science and Technology Beijing, Beijing, China \\ bianjing@ustb.edu.cn, ustblu@hotmail.com
}

\begin{abstract}
From the perspective of life course, We focused on Chinese Republic Peers women's work careers, exploiting 16 interviews on women born in Beijing between 1945 and 1959 and discussed the factors which impact on the formations of their work careers. Job shifts across different workplaces were found from most of the interviewees' experience. On the other hand, the wave mode of career movement was also conceived to be another dimension in women's occupational lives. Till the first resignation, as for the interviewees whose work careers are put into "wave mode" or "downward mode", the downward mobility mostly is related to the shifts among units while the upward mobility is mostly realized within the same unit. These typical phenomena can be considered as a consequence of the changes in Chinese society and national policies. But at the same time, the interviewees' narratives also show that these women's work careers are more significantly linked to their life events in terms of family life comparing with their husbands.
\end{abstract}

Index Terms - Republic Peers women, work career, life course, family life, interview

\section{I . Introduction}

Over 6 decades have elapsed since the People's Republic of China (PRC) was founded in 1949. Theconcomitant generation with the foundation of PRC---Republic Peers ${ }^{1}$, alongside with the newly founded PRC, witnessed many historical transitions like Great Leap Forward, natural disasters, Cultural Revolutions, Reform and Opening up and market economy development and so forth in the wake of the PRC foundation. This generation was thereby called "the Generation brought up under the Red Flag", who used to be viewed as the one to embrace the smooth growth and bright future in the socialistic big family. However, they encountered such a couple of enormous historical vicissitudes that people begin to be aware of the peculiar adversities to this generation and the inseparable relation between individual life experience and the whole society's vicissitudes. The "the send-down generation during the Cultural Revolution" and "laid-off generation" gradually become the synonyms of this generation [1]. The inseparable relation between individual life experience and society's historical vicissitudes is also explicitly reflected in the work career of the Republic Peers Women. The founding process of PRC and the legislations issued afterwards like the Chinese People's Political

\footnotetext{
${ }^{1}$ This term is commonly seen in literal works. Without explicit definition, the narrow definition nonetheless refers to the generation born in 1949, namely the year of the foundation of PRC, and growing up together with PRC. To celebrate the 60 anniversary of the foundation of PRC (2009), Chinese Communist Party History Press solicited farranging contributions to the compilation of Republic Peers collection from the society, which claimed the people born between November, 1948 and June, 1950 the Republic Peers. This paper adopts the "Republic Peers" with double meanings encompassing "historical periods" and "individual age", and meanwhile claims the people born from late 1940 s to 1950 s the Republic Peers in the broad sense.
}

Consultative Conference Common Program and PRC Constitution explicitly regulate that the female are endowed with the same right as the male in terms of political, and economic fields, cultural education and social life etc. [2][3]. Furthermore, under the inspiration of such slogans as "the equality between the sexes", "women can sustain half of the sky" and "women can do what can be done by men", during the first five-year plan from 1953 to 1958 and the Cultural Revolution, the employment rate of the female was substantially enhanced by means of country's assignment [2][3]. Afterwards, the comparatively high employment rates among the female regardless of whether experiencing life events like marriage and childbirth, were steadily maintained [4].

The career planning research in China flourished in the late 1990s, especially after 2000. However, the research arguments mainly focus on the work career planning whereas the female work career planning research after the foundation of PRC was rarely included into the research scale of sociology study, among which ref. [1] and ref. [4] are two representatives. Ref. [3] indicated that the historical events of the society after the foundation (14 out of 40 respondents) were engraved on the career planning of the female born between 1949 and 1955. Meanwhile, she also indicated that once the female of this generation, as the "the practitioner of the equality between sexes" with a strong sense of collectivism spirit, obtained assigned jobs, they didn't stop working until got laid-off, retired internally or retired officially and few of them would like to alter their workplace. In addition, ref. [4] beckoned that in accord with the national requirements like "love and delve into what you are engaged in" willingly contribute to the revolution like a screw", the "linear" career mode, under the mechanism of planned economy, is prevalent for the female born between the late 1940s and early 1950s to get an assigned job.

Besides, of the researches publicized overseas on Chinese work career, there are ref. [5], [6] and [7]. As for the research respondents, these researches are quite far-ranging, which count the Republic Peers women in but didn't specify them. But to some extent their findings still revealed that there are quite a few cases in Chinese job shifts during the work career, which differs from the conclusions drawn by ref. [1] and [4].

Based on the above research background and literature review, this paper via interview investigates the Republic Peers Women residing in Beijing and explores their work career characteristics from the perspective of life course. This paper firstly classifies the work career of the respondents and then analyzes the various elements influencing the formation 
of the work career of the Republic Peers Women from the perspectives of those important events like society's historical events and family life experience etc.

\section{II . Investigation and cohort classification}

From August 2004 to October 2006, I conducted interviews survey on 32 people (16 are women and 16 are men) who were born between 1945 and 1959 residing in Beijing $^{2}$. During the investigation, I mainly invited the interviewees to retrospect their educational experience, family life experience and work career experience and made an inquiry into their subjective comment and satisfaction degree on their different life periods. With the permission of the interviewees, I recorded the whole interview process.

At the same time, from August to September 2012, I conducted the second interview survey ${ }^{3}$ with the same interviewees to acquire the further development of the educational experience, work career experience and family life experience etc. for this generation. This paper will center on 16 women of all the interviewees and explore their career characteristics and influencing elements. This paper will mainly make use of the life-history data from 2004 and 2006. The investigation data from 2012, if needed for the illustration of work career development, will also be appropriately added.

This paper will divide the interviewees into three based on the criteria of which age periods (education periods) the interviewees are at when the Cultural Revolution started (May 1966). The specific classification methods are: when Cultural Revolution started, the interviewees who had basically finished the junior high school education or higher than that will be classified into Cohort I (CI: born between1945-50.8); those who had basically finished the primary school education or accepted incomplete junior high school education will be classified into Cohort II (born between 1950.9 -53.8); and those whose education was below fifth grade of primary school will be classified into Cohort III (born between 1953.9-59) ${ }^{4}$. The population distributions for each cohort are 5 people for CI, 5 for CII and 6 for CIII.

As described in the previous part, for quite a long time after the foundation of PRC, people thought it was pretty normal and reasonable for the students (regardless of genders) to immediately start to work right after they graduated from school. However, the interviewees basically encountered the major historical event, namely the Cultural Revolution, during

\footnotetext{
${ }^{2}$ The investigation in 2004 was sponsored by the public fund COE Program in $21^{\text {st }}$ Century from Japan Ochanomizu University: the Anthropological Developing Science from Birth to Death. Meanwhile, the investigation sample and execution received the coordination from group B of COE Program in 21st Century from Japan Ochanomizu University: the Frontier of Gender studies and Statistic Research Center from Remin University of China and its subsidiary investigation programs groups. Thereby deliver the gratitude. The investigation of 2006 was sponsored by the Kobayasi commemoration fund of Fuji Xerox Co., Ltd, Japan.

${ }^{3}$ The investigation in 2012 is part of the Chinese Ministry of Education Humanities and Social Science Fund (11YJC840001) Society's Vicissitudes and the Life Course of the Republic Peers.

${ }^{4}$ When the interviewees entered the primary school, the new semester started in September. The children who are 7 years old and born before August 31 are entitled to enter the primary school. Therefore, this paper classifies the cohorts based on August/September.
}

their senior high school (technical secondary school included), junior high school or even primary school. Due to the Cultural Revolution, in the 2 years ever since May, 1966, almost all the schools including colleges and primary schools were unable to maintain the regular school agenda. Those students in face of graduation were unable to graduate or advance in school regularly. From 1968, besides the assigned jobs to the small number of people, the majority of the graduates from college, senior high school and junior high school are sent down to the villages or the border areas. At the same time, the primary school and secondary school on one hand still implemented various education reforms; on the other hand walked into the periods to resume classes and carry out revolutions while the resumption of the College Entrance Examination was not realized until 1977 after the Cultural Revolution.

Under these circumstances, the education experience of the interviewees has to halt at certain timing. The "send-down" experience exerts the direct influence on the beginning period of individual work career. That period was compelled to substantially delayed or shifted ahead of schedule. Moreover, those who have received the relatively complete junior high school or senior high school and school beyond senior high at the beginning of the Cultural Revolution can enjoy the advantageous conditions, namely their relatively high educational background, in the smooth development of their work career. Those who didn't receive the complete junior high school, especially those encountering the Cultural Revolution at the primary school period, will suffer the consequence bred by the low quality education under the unstable social circumstances and their work career development will also accordingly be hampered.

\section{The patterns and characteristics of work career}

\section{A . The modes of job shifts among units ${ }^{5}$}

Influenced by the Cultural Revolution, most of the interviewees underwent relatively special experiences on when and how to be assigned with the first job. Among them, some advanced the assigned jobs because they failed to go to the university they dreamed about while others hadn't been assigned with jobs until 2-3 years later or even 10 years later due to the "send-down" policy. Thus it can be seen that the suspense of the educational experience and the absence and presence of the "send-down" experience influenced to a large degree the formation of their work careers.

In addition the in-service study time, ( with the premise of the unit's permission, it refers to the time when no work is involve but only experience the full-time study of specialty), all the interviewees have never suspended their jobs from their first assigned jobs till the first resignation ${ }^{6}$. In terms of work

\footnotetext{
${ }^{5}$ It is a term which means organization or economic sector in China.

${ }^{6}$ In the investigation of 2004, except Ms I and Ms M who are still in-service, the rest all left their work units, once regarded as the "iron bowl" via laid-off, internal retirement, buy-out or official retirement etc. and faced the termination of their work career or tremendous transition. I claim this phenomenon closely related to the society's historical vicissitudes "first resignation" to differentiate the "re-employment" of the interviewees in the subsequent market economy mechanism and the further development of their work career.
} 
career development, I classify their work career into "shifting mode among units" and "non-shifts mode" based on whether they have ever changed their work units, among which there are 11 people for the former mode and 5 people for the latter

one. If counting the re-employment after the first resignation in, the investigation on the whole process of the interviewees' work career turns out that there are 14 people for "shifting mode among units" and 2 people for "non-shift mode". The conclusion can be drawn that the shifts among work units are still prevalent even though the interviewees haven't experienced the work suspension.

The interviewees' shifts among work units happened from 1972 to about 2000. At the same time, after the reform and opening-up speed in 1992 is accelerated, so are the shifts of the interviewees' work career among work units. After the mid 1990s, 14 people out of 16 underwent the first resignation, especially the age of the first resignation of CIII is younger than the ones of the first resignation of CI and CII. The job shifts among work units are sticking out by means of reemployment after the first resignation.

\section{$B$. The career modes shifts}

As is illustrated in table 1, according to the given classifications of different careers by labor economics, I classify the interviewees' careers they have been engaged in into such 5 modes as hired labor service (a), sale (a'), clerical work(b), professional•technological•managerial (c) and nonhired self-employed. The careers from labor service and sales to business (self-employed) and to professional - technological - managerial work are undergoing the upward mobility in terms of the careers' self-discipline and specialization. Meanwhile, those shifts usually see the concomitant rise in occupational status from workers to cadres. Hence in the following analysis, I denominate work career moving from $\mathrm{a}\left(\mathrm{a}^{\prime}\right)$ to c "upward mode". In contrast, I denominate the work career moving from $\mathrm{c}$ to a (a') "downward mode". Accordingly, the work career without upward or downward mobility is denominated "level mode" while the work career without repeated upward and downward mobility is denominated "wave mode".

\section{The relation between the work units shifts and career modes shifts}

Till the first resignation, as for the interviewees whose work careers are put into "wave mode" or "downward mode", the downward mobility mostly is related to the shifts among units while the upward mobility is mostly realized within the same unit. For example, Ms. A, Ms. B and Ms. D of CI, Ms. J of CII and Ms. L and Ms. P of CIII undergo work career downward mobility which is related to shifts among units. Meanwhile, the work career upward mobility of the female including Ms. B, Ms. C and Ms. E of CI, Ms. J of CII and Ms. $\mathrm{O}$ of CIII is also inseparable from the internal shifts within the units.

Overall, some interviewees also believe that the shifts among units (before the first resignation) provide important life transitions, nevertheless in most situations, the shifts among units are related to the downward mobility of the work career modes. Just as Ms. K of CIII put it, "the frequent work shifts are not favorable to the employee himself". The shifts among different units brought forth unfavorable influence on the work career development of these women.

\section{The influencing elements of the work career development}

The historical backgrounds at the macro level, the units' development trajectory and the family life at the micro level all together yield influence on the formation ofthe women's work career.

Firstly, historical background influence is visible throughout the following cases analysis. Ms. B of CI failed to go to college due to the Cultural Revolution in her senior year at the senior high school, which to a large extent impacted the development of her work career in the later years. Furthermore, the following phenomena are all without exception related to historical backgrounds: people of CII mostly underwent the "send-down" experience prior to the assigned jobs; the age of CIII to experience the first resignation is falling and Ms. $\mathrm{P}$ started her own business after the country allowed the development of the self-employed.

The developing trajectory of the units varies due to the difference among enterprises (state-owned, collective enterprises etc.), government agencies or public institutions. After 1990s, the enterprises' reforms, especially the stateowned enterprises' reform have been in full swing. In 1971, Ms. B (16 years old) attained the assigned job as a worker in the workshop of the factory after graduated from the junior high school and due to the reform her work career was not stable any more correspondingly. She had never thought of leaving the factory whereas she became one of the first batch of laid-off workers in 1994 (39 years old) due to her gender and poor health.

However, she had to start again to look for new jobs to contribute to the household spending because her children were still in the primary school. She sold stuff, swept the street and worked at the reception room as well. These frequent shifts formed the stark contrast with her previous 23 years of stable worker life. Compared with the state-owned enterprises, it is comparatively stable to work in the government agencies and public institutions, which contributed to the relative stability of Ms. F of CII (researcher of certain Institute) and Ms. I of CII (certain secondary school teacher). But ref. [6] pointed out that most of the people who were able to enter the government agencies or public institutions in 1960s and 1970s earned their college degree or senior high school diploma prior to the Cultural Revolution. In this research, it is easy to spot the linkage between the relatively stable work career among the female and their relatively high degrees or diplomas to a large extent.

The above are the brief analysis on the influence of historical backgrounds at the macro-level and units developing trajectory between macro scope and micro scope. The study on the influence of female family life experience on their work 
career through specific cases is far from adequate, whether domestically or internationally. Therefore, in the subsequent part, this research will pivot to micro level, specifically exploring the influence of family life experience of the Republic Peers Women on the formation of their work career.

\section{The linkage between work career and family life experience}

First of all, the mounting residence shifts and housework in the wake of the marriage, many women were unable to continue the long distance commute as usual. Encountering this kind of problems, the women generally chose to alter their work units to take care of their family life and work career. Of the interviewees in this survey, the experience of Ms. K and Ms. M of CIII are two typical samples. From the examples we can conclude that whether the labor burden is overweight might be one reason for the women to transfer their jobs but it is definitely not the determinant. Besides the labor burden, the women won't choose to shift among units unless when the commute time is long and the women are unable to give consideration to family life and work career. The job shift for the husband is also another possible choice. But under this circumstance, the common feature of these two examples is the wives' shifts instead of the shifts of the husbands.

Another juncture for the women to choose the work shifts appears when the women need make adjustment to the childbearing and their work. Ms. A, Ms. B and Ms. E of CI and Ms. P of CIII mentioned the impact of the childbearing on their work career.

After the baby period and further entered the schoolattending period, the women still chose to shift among units due to the children's life or education problems. Ms. D of CI, Ms. F and Ms. J of CII, and Ms. L of CIII all underwent the similar experience. The conclusion can be drawn from the cases' narratives that when the continuation of the work career and mother roles like taking care of the children or providing support for the children's education and entering a higher school clashes, the women of this generation will generally give preference to choose the mother role.

The family life import events like looking after family members are significant elements in the late work career of the Republic Peers Women. For instance, Ms. B of CI voluntarily asked for the unit interior retirement in 1994. Later on, after several twists and turns, she founded her own company in 1999. Although the business operation of the company is fairly good, her husband was diagnosed with cancer in 2002 when she was 55 years old. Ms. B thought that it was better to take care of husband herself than hire someone else to do that. Therefore, Ms. B dismissed her company and went home to attend to her husband full time. Every day she decocted the Chinese herb, cooked the dinner and took her husband to the suburban are for fun. Under the intensive care of Ms. B, her husband was restored pretty well. In the second interview in 2012, Ms. B and her husband were happily taking care of their five-years-old grandson. In the meantime, Ms. C retired in 1993 when she was 46 years old. Later on, she didn't immediately look for new job while instead she brought her father from her brother's home to her home and took care of her father by herself and she was not employed until her father died.

\section{V . Conclusions and discussion}

First of all, this research classifies the work career of the 16 interviewees and then accordingly explores mainly the influence of historical events and the important events in individual family life experience on the women's work career of this generation. In the literature review part of this paper, ref. [1] points out that the female workers are rarely altering their work units before the interior retirement or the official retirement. This research turns out to find that the "job shifts among units" exist even if in the work career before the first resignation. If the re-employment after the first resignation was also counted in, it is more common to the "job shifts among units" among the female. At the same time, contrary to the general impression that work career of the female mostly presents "linear mode" [4], this research finds that there are pluralistic modes including the "wave mode" (the repeated occurrence of upward mobility and downward mobility) in terms of the work career shifts of the female work career.

Ref. [5], [6] and [7] all pointed out that it is not rare to see the job shifts among units among the city residents in China. As for the reasons of the shifts, ref. [6] thought that it was related to the country's policies like "Great Leap Forward", the Cultural Revolution and large crowds' returning to city after the "send-down" experience. Indeed, in plannedeconomy period, people regardless of their gender attained the job assigned by the country. The individual had neither freedom nor necessity to choose their career [3]. Under the influence of the work career policies dominated by the country, the Republic Peers Women also attained their assigned jobs to start their work career.

For the other side, this research also finds that either during the Cultural Revolution period from 1966 to 1976 or the period after the Cultural Revolution from 1976 to 1985 , or the period after the city reform and opening-up started from 1985 to 1992 , or the period when the city reform was accelerated after 1992, the Republic Peers Women all underwent the work shifts among the units. Furthermore, these shifts are not only related to the country's policy, but also closely related to the events of the family life experience such as the married, childbirth, childbearing, children's education and looking after family members after the middle age. The Republic Peers Women who attained their job through the country's assignment had no freedom to choose their first work career. Nevertheless, it was because they didn't have such freedom that they had to alter the assigned initial job and to adjust their work career concomitant with the carrying-on of their family life experience.

However, this research also finds that most of the female in this generation had no such awareness as overburdened role or "conflicts between work and family". As for them, even though it was a tough period for them to take care both of their 
work and their family, they had never thought of giving up their work before the first resignation. These concepts like making adjustment within the possible range and maintaining the life style of both work and taking care of family have been deeply imprinted on their mind.

Concomitant with the foundation of the PRC, the women liberation movement aimed to realize the equality between women and men and it was not the liberation movement for one city resident whereas it was carried out as the country's policy. Certainly, it turned out that people accepted the "the equality between women and men as the reality. Correspondingly, the employment rate of the women was substantially improved. Integrated with thousands of years' history, many traditional cultural norms like "men are superior to women" and "men played the role as breadwinner while women were confined to the family", have deeply influenced on people's cognition. Therefore, when the work and family clashed, women will voluntarily undertake the family duty and make units shifts, leaving the successful career chance to their husbands. Hidden in the female high employment rate, even the women aren't fully aware of the role division consciousness, namely "men play the role as a breadwinner while women not only play the role as breadwinner but also take care of the family" [8], which mediated the conflict among women education, career and family life. Nevertheless, with the deepened reform, when the work career freedom is increasing and the labor force market competition is more severe, the number of the Republic Peers Women who experienced the first-resignation is also rising.
In the future research, in terms of understanding the work career of the Republic Peers Women and their family life experience, we should pay attention to the variability and invariability of people's conscious levels in addition to "the clashes between work and family life". By comparing the differences between the Republic Peers Women and the men from the same generation or other younger women's experience, the further exploration should be studies as well.

\section{Referencs}

[1] X. Tong, Alienation and Struggling---Chinese women work history research, Beijing, China social science publishing house, 2003.

[2] X. Tong, "The history and tendency of social vicissitudes and China women's employment," Collection of Women's Studies, vol.1, pp38-41, 1999.

[3] Y. P. Jiang, "China city women employment under two mechanisms", Collection of Women's Studies, vol. 1, 2003, pp15-21.

[4] G. M. Wu, The Study on China Women Work Career Development, Beijing, China social science publishing House, 2004.

[5] N. Nagase, Y. Murao, "Chapter 5 work careers", An international comparative study on family, work and family-economic: the first year report of the panel survey in China, group B of COE Program in 21st Century from Japan Ochanomizu University: the Frontier of Gender studies, pp66-94, 2005.

[6] X. G. Zhou, N. B. Tuma, P. Moen, , "Institutional change and job-shift patterns in urban China, 1949-1994", American Sociological Review, vol. 62, pp339-365, 1997.

[7] H. F. Ge, The generation of the Chinese Great Cultural Revolutions, Tokyo: Akaisisyoten Press, 1999.

[8] Y. P. Jiang, "'Great Discussion on "Staged Employment" and "Women Go Home at the Turn of the Century", Collection of Women's Studies, wol. 2, pp23-28,2001. 